\title{
Poor Settlements in Chittagong city, Bangladesh: The context of Pollution and Health Risk
}

\author{
Alak Paul ${ }^{*}$, Md Nakib Haider' ${ }^{1}$ and Naznin Nahar Sultana
}

1 Department of Geography and Environmental Studies, University of Chittagong, Hathazari, Bangladesh Corresponding Author (paul.alak@ cu.ac.bd)

Received:13 Nov, 2019

Revised: 17 Dec, 2019

Accepted: 05 Jan, 2020

Published: 28 Jan, 2020

How to cite this paper: Paul, $A$., Haider, M.N., Sultana, N.N. (2019). Poor settlements in Chittagong city, Bangladesh: The context of pollution and health risk. Quest Journal of Management and Social Sciences, 1(2), 233-250.

Copyright (C) 2019 by authors and Quest Journal of Management and Social Sciences

This work is licensed under a Creative Commons Attribution-NonCommercial-NoDerivatives 4.0 International License.

https://creativecommons.org/licenses/by-nc-nd/4.0/

\begin{abstract}
Background: The rapid rate of urbanization in Bangladesh has created some adverse effects on the overall urban environmental health of the cities. Among all, mass poverty, expansion of poor neighbourhood, inadequate supply of urban services such as water, sanitation, waste disposal etc. are mostly responsible for health risks of urban people particularly in low income areas.
\end{abstract}

Objective: The aim of this paper is to determine the health risks of the environmentally poor neighbourhoods in Chittagong city by exploring the discourse of pollution, risk, and stigma.

Methods: The study is predominantly based on qualitative data collection methods like participant observations, a case study and FGDs. The method has delivered an indepth understanding of the pollution-related risks, the physical and mental sufferings of the urban poor due to pollution. Though it is solely a qualitative study, the study is complemented by a quantitative survey method and personal interviews.

Findings: The study revealed that there are two leading environmental risk factorsthe structural setting of the neighbourhood and coping practices to everyday life of the poor settlers, who affect the neighbourhood environment. The poor structured living houses, shared kitchens in the environmentally hazardous area, dirty playgrounds, unhygienic latrines, and waste disposal sites near neighbourhoods enhance the risk of diseases and injuries for inhabitants. Similarly, lack of access to pure drinking water, fuel, are generating health risks. Consequently, dwellers, especially women and children, suffer from cough and cold, diarrhoea, gastric/acidity, worm disease, respiratory illness, scabies, headache, allergy, and jaundice regular interval of time.

Conclusions: The study concludes that physical structure of the neighbourhood, and the physical and mental sufferings of its inhabitants are interdependent. To reduce the sufferings of inhabitants and their health hazards can be reduced with the combined efforts of the Government and the NGOs and the local people as well.

Implications: This findings of the study can be useful to the concerned authorities of Bangladesh in planning appropriate policies to control pollution and minimize health risks. For that purpose this study can serve as reference.

Keywords: Poor neighbourhood, Pollution, Urban environment, Health risks, Bangladesh

Originality: This paper is original and is not sent for publication in other publications

Paper Type: Research paper

JEL Classification: I1, I3 


\section{Introduction}

The world urban environmental quality is deteriorating more and more with the population explosion, rapid urbanization, and industrialization. This situation has imposed different types of risk factors on human health as the environment more strongly affects people's health than any other determinants (Morgan, 1991). Over the last three decades, there has been increasing global concerns over the public health impacts attributed to environmental pollution, particularly in the burden of disease. The World Health Organization estimated that about a quarter of the diseases facing mankind today occur due to prolonged exposure to environmental pollution (WHO, 2008). Since environmental pollution predominantly occurs in the urban areas of the developing countries, urban people are at the centre of different environment-induced diseases. Hence, the issue of understanding and managing urban environmental health has become a major concern for many of the developing countries like Bangladesh. Urbanization is occurring rapidly in Bangladesh, accompanied by the proliferation of slum settlements. The residents face health problems due to adverse social, economic, and public environmental conditions in their neighbourhood (World Bank Report, 2018). Not all the neighbourhood has condition of environmental health as the built environment differs from one locality to another. The worst may be experienced in a poor neighbourhood or settlement as it lacks the availability and quality of services (Ellen and Turner, 1997).

Chittagong is the second-largest city and commercial capital of Bangladesh. The population of Chittagong City Corporation (CCC) grew from 2.06 million in 2001 to 3.56 million in 2016 (BBS, 2015). The population growth primarily caused by rural-urban migration of the poor from environmentally vulnerable and economically depressed areas. On arrival, these poor migrants routinely move to slums and squatter settlements for shelter in absence of money and resources. Therefore, the number of slum clusters within the city is increasing day by day. In 2005 the total number of slum clusters in CCC was 1814 (Islam et al., 2006). Recently the number reached to 2215 (BBS, 2015) though, the environmental conditions and access to basic urban facilities in these slums have not developed much. These slum clusters represent poor neighbourhoods. A wide number of studies indicate that these slums are characterized by poor environmental services with a high level of pollution (GOB, 2015). Accordingly, a large number of slum residents live under varieties of physical health threats including environment-induced diseases. Since the migrants enjoy very healthy rural environment before migration, they go through mental distresses to adjust polluted and unhealthy surroundings of neighbourhood.

Slum residents are especially vulnerable to health risks (Mannan, 2017). The 'polluted' air and water, unhygienic sanitation facilities, poor waste disposal system and inadequate housing structure in the neighbourhood are the key factors responsible for environmental health risks. These factors are directly causing physical 'risk' of diseases and injuries. Poor environmental conditions, coupled with the physical 'risks', generate mental sufferings which lead them towards stigmatization. However, the existing studies mostly provide an overview of physical health problems, illness, or vulnerability of the slum people (Mannan, 2017; Hossain Moniruzzaman, and Islam, 2010; Smith, Samet, Romieu, and Bruce 2000; Islam et al., 2006; Smith, Corvalàn, and Kjellström, 1999; Hutton, Haller, and Water, 2004; Ivanov, 
Licari, and Bertollini, 2004) by poor socio-economic condition (Rahman, Haughton, and Jonas, 2010; Smith and Ezzati 2005; Hossain et al., 2010; van Eenwyk and Brandt, 2013). Yet, in-depth understanding of how or in what ways the polluted environment is triggering specific physical and mental health risks has remained mostly unanswered in the literature. Considering the condition, the present research aims to answer the research question- How do the living environments of the poor settlements cause health risks of the inhabitants?

The study reflects the relation between existing health problems and their surroundings and the access they have with basic needs. The outcome revealed evident connections among social, economic, and environmental contexts to produce health risks for the poor of the slum. Furthermore, the disease pattern they suffer regularly by different gender and age group have linked with the vulnerable conditions and surroundings they handle daily. The central focus of this inductive-empirical research is to understand the influence of poor environmental neighbourhoods on the health of the inhabitants through exploring the contexts of pollution and risk. The findings of the research will offer indication for the government projects and policy as well as a functional outline to NGOs working on developing the urban slum environments and health of the slum residents throughout the country.

Section 2 of the paper critically examines selected recent literature. Section 3 presents the methodology and data sources. Section 4 presents results and discussion. Conclusions are given in section 5 .

\section{Review of Literature}

Environmental health is defined as health outcomes that are a result of environmental risk factors (Breman, Alilio, and Mills, 2004). The World Health Organization has defined environmental health as "all the physical, chemical, and biological factors external to a person, and all the related factors impacting behaviours. It encompasses the assessment and control of those environmental factors that can potentially affect health (WHO, 2008). However, a poor neighbourhood is not just a place of poor people, but also a place of a poor environment. Several types of research identified different environmental problems in poor neighbourhoods. Hastings, Flint, McKenzie, and Mills, (2005) found that the poor and deprived neighbourhoods usually have extreme population densities with higher rates of economic inactivity which possess some common characteristics of different types of pollution that may affect environmental health. Moreover, limited opportunities such as fewer parks, lack of open space for physical opportunities obstruct physical exercise compared to wealthier neighbourhoods (VanEenwyk and Brandt, 2013).

According to the prevailing studies, three types of major environmental problems are observed in poor neighbourhoods. First, indoor air pollution from smoking, solid fuels is the most common environmental problem in urban poor settlements (Sanbata, 2014; Smith and Ezzati, 2005). Second, access to pure or usable water and hygienic sanitation is a growing demand in the cities across the world. Most of the developing countries are off-track to meet water supply and sanitation requirements of MDGs in urban areas, particularly in the low-income areas of towns (Rahman et al. 2010; Smith and Ezzati 2005). Third, cities are at the 
nexus of a further threat to the environment due to the increasing quantity and complexity of wastes. In many cases, municipal wastes are not well managed in developing countries with the accelerated pace of waste production (Chalmin and Gaillochet, 2009). Furthermore, waste collection services are generally non-existent in poorer neighbourhoods such as slums (UNEP, 2010; Hossain et al., 2010).

Nevertheless, such environmentally poor conditions certainly affect human health. International organizations namely, WHO, UNICEF have comprehensively reported that tackling environmental health issues is crucial (WHO, 2008) as 24 per cent of the global disease burden and 23 per cent of all deaths can be attributed to environmental factors (Prüss-Üstün and Corvalán, 2006). As a result, the inhabitants of poor settlements confront the risk of Respiratory Infections (Smith et al., 2000); Malaria (Islam et al., 2006); Dengue (Heukelbach, de Oliveira, Kerr-Pontes, and Feldmeier, 2001); Cardiovascular Disease (Cohen et al., 2004); Chronic Obstructive Pulmonary Disease (Smith et al., 1999); Asthma (Xu, Niu and Christian, 1996); Diarrhea (Hutton et al, 2004); Intestinal worms, Malnutrition, Anemia (Ivanov et al., 2004). Importantly, most of the studies depicted that the burden of poor environmental health falls on the most vulnerable of the poor, mainly children under the age of five, women, disabled and elderly.

A good number of quantitative studies assessed the environmental condition or the environmental health of urban poor neighbourhoods in Bangladesh. The study of UN-Habitat (1996) identified the environment (condition of roads, drainage system and garbage disposal system) of slums as dirty. The hygiene knowledge and practice both are low among inhabitants (Hossain et al., 2010) The households in destitute areas are very exposed to localized environmental problems (Rahman et al., 2010; Hossain et al., 2010) and thus necessarily developed a wide range of coping strategies around the living space (Rahman et al., 2010). The disease pattern of the slum dwellers strongly affected by unhygienic lifestyle such as smoking, sanitation (Hossain et al., 2010), use polluted water (Rahman and Rahman, 2013; Alam, 2013) which largely related to asthma, diarrhoea and skin diseases (Shil, 2013). Additionally, indoor air pollution using solid biomass or raw fuel seriously affects human health particularly new-borns and children (Haider, Rahman, Islam, and Khan, 2016).

The slum residents often find themselves enveloped in a battle for survival against disease, inadequate shelter, a lack of basic services and poor nutrition (Mannan, 2017). Every aspect of a slum resident's life is adversely affected: their emotional well-being, physical security, mental development, and overall health. It deprives them of the right to live in a hygienic environment, exposing them to a world of violence, abuse, and exploitation. Slum children whose rights to safety and dignity are denied are the worst sufferers. They become victims of exploitation, violence, and abuse, which rob them of their childhood, preventing them from fulfilling anything close to their full potentials. The existing studies largely focused on the quantitative estimation of urban environmental problems in low-income areas. There are a few attempts to support these statistics with an in-depth understanding of the everyday socio-economic and environmental struggles of the destitutes. Therefore, it is expected that the present research will be an endeavour to fill up these research gaps. 


\section{Research Method}

Both quantitative and qualitative methods were used to explore the relative locations of different establishments as causes of pollution, and the influence of structural setting to physical and mental health risks. The quantitative technique was applied for collecting information about the neighbourhood and the different types of diseases that the people suffer from while qualitative study delivered an in-depth overview of everyday struggles resulting in health risks. The study has been completed mainly by primary field survey. Moreover, secondary data was collected from different sources, both published and unpublished materials. The primary quantitative data were analysed with SPSS and qualitative data (case study and FGDs) scrutinised by following Grounded Theory method (Kitchen and Tate, 2000)

The study areas were selected by using purposive sampling method. For instance, the slum areas which encompass common and familiar characteristics of dilapidated and incomplete housing structure, low level of infrastructural facilities, closely packed and inhabited by impoverished people. The slums also lack well-structured sanitation system, the supply of clean drinkable or usable water, reliable electricity line, healthy waste management process, secure kitchen arrangement, green or open space, playground, and other basic services. The survey was conducted at Tankir Pahar Slum of Lalkhan Bazar (Ward no. 14); Zahangir Colony of Sulakbahar (Ward no. 8); Chairman Colony of Jamal Khan (Ward no. 21); and Fulbagan Bustee of West Sholo Sohar (Ward no. 7) of Chittagong City Corporation (CCC).

The study areas are a small neighbourhood altogether containing approximately 1280 houses (Table 1). The 'Snowballing method' was followed to identify slum and total household number through enquiry local elderly inhabitants. By considering each household a unit, the head of the house has been interviewed through a semi-structured questionnaire and checklist by following perception and opinion survey. The houses were taken by stratified random sampling. The sample size was chosen 320 (by following the general rule of thumb) which were $25 \%$ of the total houses of the neighbourhood. With the guidance and participation of authors, a survey team including four trained field investigators collected primary data from December 2018 to March 2019. The field investigators were postgraduate research students of Department of Geography and Environmental Studies, University of Chittagong, Bangladesh.

Table 1: Sampling Framework

\begin{tabular}{|l|r|r|}
\hline Name of Slum with Ward number & Total number of Houses (Approx.) & Sample Size \\
\hline Tankir Pahar (14) & 400 & 100 \\
\hline Zahangir Colony (8) & 320 & 80 \\
\hline Chairman Colony (21) & 240 & 320 \\
\hline Fulbagan Bustee (7) & $\mathbf{1 2 8 0}$ & 80 \\
\hline Total & $\mathbf{3 2 0}$ \\
\hline
\end{tabular}

Source: Field survey, 2019 (Authors'own calculation)

For qualitative surveys such as case studies and FGDs, the respondents were taken by purposive sampling considering the people who are the worst sufferers of pollution, both physically and mentally. Each of the interviews with the respondents took 35-40 minutes. To represent research outcomes mainly descriptive analysis was followed. 


\section{Data Analysis and Result}

\section{Neighbourhood structure and health risks}

The structural setting first includes the housing pattern of the inhabitants. It involves the row material used to construct the houses, the number of rooms these contain and the size of the rooms. The low-income residence is unable to afford minimum conventional dwelling or housing. Moreover, there is an acute shortage of housing for this group (Gurumukhi, 1984). The use of indigenous materials (e.g. mud to build floor, reeds, or bamboos to build walls etc.) dominates the housing patterns. The houses built of these materials lack structural stability and durability which in turn depend largely on the judicious selection of materials and sound structural design. Thus, these houses cannot provide a cost-effective return to poor users (Amin et al., 1998). It has been found in CUS report that about $66.6 \%$ of the slum houses of Chittagong city are of very poor quality (CUS, 2011; Islam et al., 2006; Prosun, 2011; Ahmed, 2014). The low quality of housing is one of the most basic indicators characterizing slum settlements. The present research evaluated housing pattern defined by the floor, wall and roof type of the houses, the number of rooms occupied by each family and the sizes of those rooms.

During the study, it has been found that the majority of the houses (92\%) in the study areas consist of only one room. These were prepared as a one-roomed house by the landlords keeping in mind that the poor people cannot afford the cost of the houses with more than one room. As Faizul Haque, a landlord and a political leader of Fulbagan area had the opinion during an FGD,

"A one-roomed house in Fulbagan costs at least 1200 taka and thus a two-roomed house should cost not less than 2200 taka per month. I suppose most of the families living in this slum have monthly income not more than 5000 taka. So, how can they spend that much money (220o taka) as house rent?"

Furthermore, more than two-third families (about 69\%) consist of 4-6 members and many of them (14\%) consists of more than 6 members (Figure 1). These people are mostly illiterate and unaware of family planning. They think of having more children so that they (children) can contribute to family income as they grow up.

A large family generally needs a large space to live in. But the room sizes of the oneroomed houses of the study area are not too big. The average room size of most of the houses (47\%) in four study areas ranges between 101-125 square feet. Nearly eighty per cent of them have room size less than 125 square feet (Figure 2). Thus, in most of the tiny houses in the study area, about 4-6 members live, taking their food and keeping all the goods in one room that they are using. Jahura, who has 6 family members and one room to live, told, "It is too hard for 4 people to live in this small room. But we need to live with 6 people. What we can do? We don't have enough money to rent another room."

The people of the study areas get an average floor space of 22.75 square feet per person (considering mean family size as 5 and median of floor space as 113.75 square feet). In fact, large floor space in all the houses is occupied by furniture and other household goods like water baskets, dinnerware etc. thus reducing the actual floor space available for the family members to sleep. This low actual floor space makes them think of their house as even more 
crowded and congested. That is why all the members of a family are not found inside the house at day time except during sleeping at night. Sleeping in a congested house is distressing for them. Kulsum, an old lady of Chairman Colony said, "At night we four siblings have to sleep here, lying close to one another within this tiny space. For this reason, if anyone of us is affected by any disease, we all have to suffer from the very same disease." Thus, crowding is making them more vulnerable to diseases due to the dwelling structure which has also been supported by previous studies (Beggs and Siciliano, 2001; Dunn, 2002; Kempson, 1999). Overcrowding is associated with the transmission of tuberculosis (Stein, 1950) and respiratory infections (Fonseca, 1996). Lack of enough space in the house also contributes to morbidity from respiratory infections and activation of tuberculosis (Conway, 1993) meningitis, typhus, cholera, scabies (WHO, 2015).

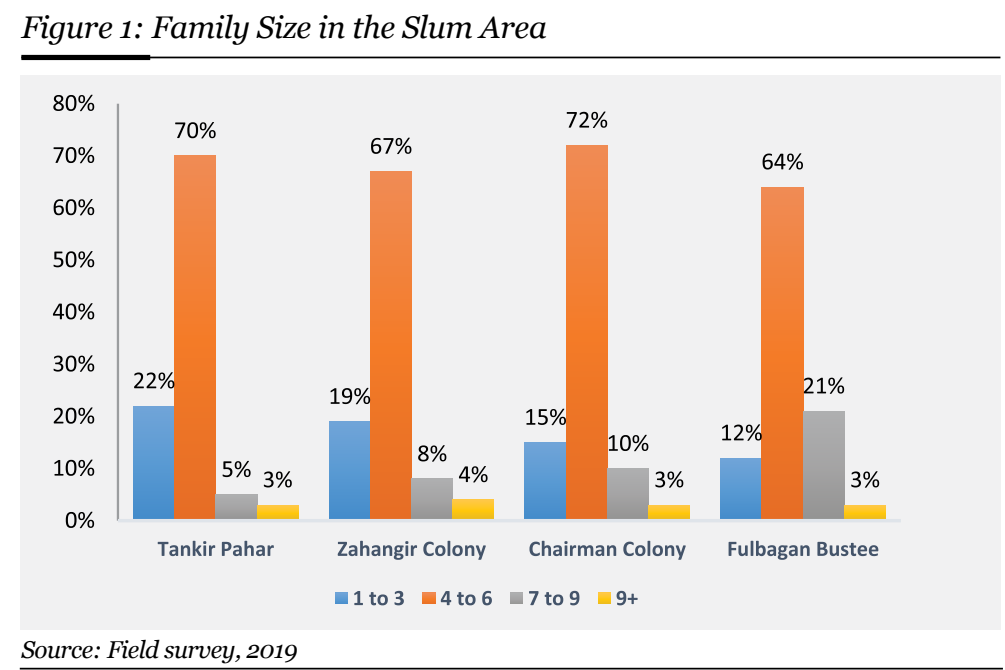

However, more than two-thirds (63\%)of the houses characterised with the muddy floor, tinned roof and either tinned or thatched (generally made of bamboo) walls are very common there. During the field survey, it has been found that very insignificant portion (less than $1 \%$ ) of the houses of the neighbourhoods have bricked roofs. The roofs of most of the houses (91\%) are made of tin (Figure 3). Rest of the people afford plastics as the roof of their houses. Few houses have holes on the tins resulting wet condition during rainy days. They use plastic buckets underneath the holes to hold the rainwater. The dwellers sleep on these muddy floors at night as they cannot afford a bed for all of the family members. As a result, they handle the risk of different diseases. Karim, a rickshaw puller of the poor neighbourhood said, "I cannot afford a bed for my children. They place empty plastic packets of cement on the muddy floor and sleep on it. They have to sleep on it even during the rain also. That is possibly the reason why they always have a cough and cold and skin diseases". Additionally, diarrhoea, a leading killer of children in the developing world, spreads more easily in homes with dirt floors. It also assists in the spread of respiratory and parasitic diseases. As cleaning the floors that are made of mud is so difficult, a faecal matter brought in on shoes or from dirty water spilt indoors tends to stay put, and children are especially likely to ingest it (NPR, 2014). 
Moreover, all the houses of the neighbourhoods lack proper ventilation. There is no way of sunshine and air can enter the houses properly. The switch on lights even during daytime and when load shedding occurs, they live in day-darkness and enhance the risk for the inhabitants. The damp houses provide a nurturing environment for mites, cockroaches, respiratory viruses, all of which play a role in respiratory disease pathogenesis headaches, fever, nausea, vomiting and sore throats (Krieger and Higgins, 2002).In recent years,

Figure 2: Room Size of the Houses in the Slums

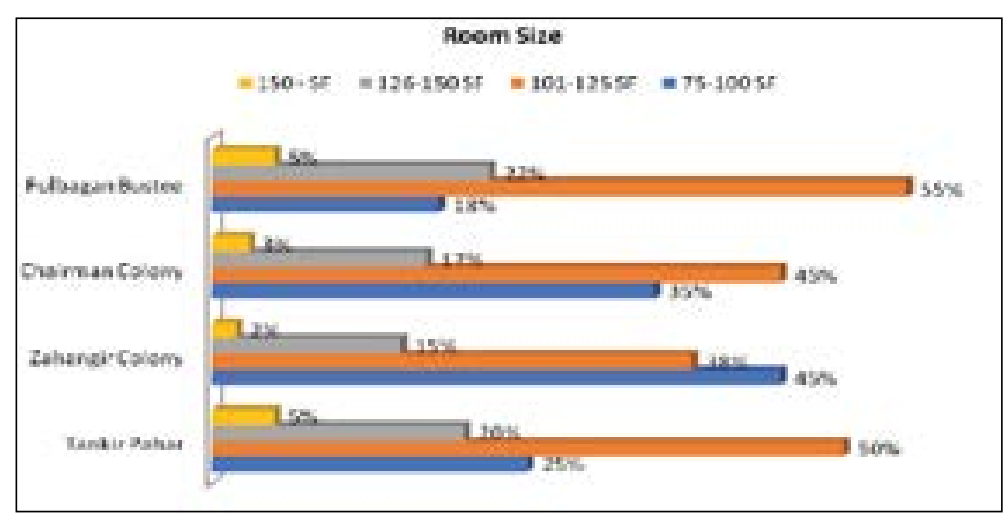

Source: Field survey, 2019 (Authors'own calculation)

epidemiological studies (Sears and Genuis, 2012; Krieger and Higgins, 2002) have linked substandard housing with an increased risk of chronic illness. Studies represent that overcrowding and inadequate ventilation increase interior moisture. On top of that, about $91 \%$ of the walls of the houses of the neighbourhoods are made of both tin and bamboo which mentioned here as thatched. These weak and unstable structures of the houses push them into the vulnerability of injuries during wind, heavy rain, and thunderstorms.

Nevertheless, the inhabitants use the shared kitchen which in most cases located near the latrines. As the latrines are always kept open, there is a possibility that flies carry germs from these latrines and spread those germs. Therefore, cooked food in the kitchens get could be contaminated by germs easily. Insects including flies and cockroaches, and rodents, such as rats and mice, can spread germs to food when they crawl or walk over and may cause sickness of people. According to the Australian Government Report (2010), the diseases that may occur from these germs are - Hepatitis A, gastrointestinal illnesses (food poisoning, gastroenteritis, and acute diarrhoea), infections of the skin and ear, colds and flu, trachoma etc. In some clusters, the kitchens are in the middle of the cluster surrounded by houses. During the main cooking time (11 am-1 pm) when most of the families cook food in their shared kitchen, the huge volume of smoke generated from burning of fuels spread all over the cluster. This smoke also enters inside the surrounding houses through the doors. This smoke can cause respiratory illness (through indoor pollution) of the people resting inside the house.

Apart from food, the playground has an enormous contribution to brain development. Playing opportunity also linked to motor skills, and social capabilities (Perry et al, 2000; Rivkin, 2000; Lusich, 2011). All learning-emotional, social, motor and cognitive-is accel- 
erated, facilitated, and fuelled by the pleasure of play. Children of the poor neighbourhood are highly vulnerable to contamination. They breathe more air than adults and thus face a higher risk of airborne diseases. The playgrounds with as blades, needles and broken glasses have the potentiality of causing injuries to the children. Not having the necessary experience to identify dangers, they often run on these things and get injured by cutting the skin of their legs. Some younger children even put those things in their mouth which can cause internal bleeding and result in serious injuries.

Furthermore, the playground of the study areas filled with domestic waste and animal faeces. These faeces contain different harmful germs and bacteria for children. In the absence

Figure 3: House Types in the neighbourhood

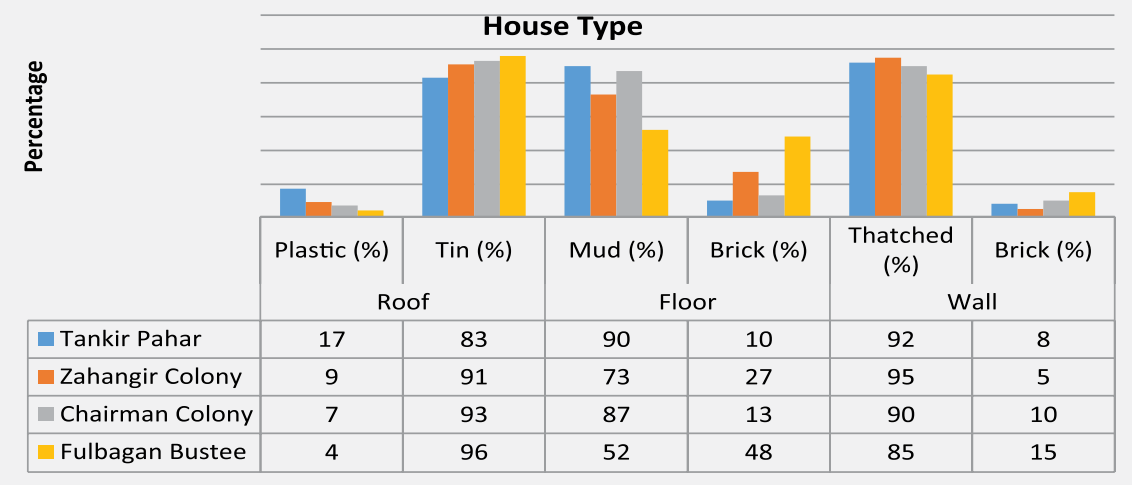

Source: Field survey, 2019 (Authors'own calculation)

of an adequate playground in the few neighbourhoods, children play in vacant land just beside a drain. These dirty playgrounds are probably nurseries for a host of diseases. One of the mothers pointed out the issue as "It is too hard to take proper care of my children in parallel with the household chores. Moreover, who will take care of my children when I go to work outside? So, on that time they play in mud and dust and get scabies and worm disease."

\section{Access to water, sanitation, waste disposal and health risks}

According to the Joint Monitoring Programme of the World Health Organisation (WHO) and UNICEF, access to improved drinking water sources in urban areas of Bangladesh has declined from $88 \%$ in 1990 to $85 \%$ in 2008 . The situation is worse for slums though lack clear statistics on the issue. A survey on living conditions of the urban poor in Bangladesh reported that nearly, 60\% respondents suffer from water-sanitation-hygiene related diseases (UNICEF, 2011). The main source of water for drinking, cooking and bathing in the study areas is deep tube well. About $69 \%$ of the people in the study area use deep tube well water. According to the people in the neighbourhood, these deep tube wells were established by PSTC, and UNDP under UPPR,P. People share these deep tube wells. Though most of the people in the neighbourhood use this water, they call it 'iron' water because of visibly high presence of 'iron' in the water. When 
the deep tube well water is collected and kept in a jar, drum or a bucket for few hours, a brown layer forms and the water looks unappealing. As they do not have access to other source, they use this water. One respondent opined in an FGD, "We don't have any better option other than using deep tube well water. We don't even know whether this high amount of iron is harmful or not. God knows what harm it will cause to our health in the future."

Along with pure usable water, well-structured sanitation can reduce many diseases and maintain good hygiene. In the studied neighbourhoods, more than half (54\%) of the people have access to pacca (brick structured) sanitary but shared latrines. All these latrines are shared by the people living in the neighbourhood. These latrines were mostly established by different NGOs like Population Services and Training Center (PSTC), and United Nations Development Programme (UNDP) under the Urban Partnership for Poverty Reduction Project (UPPRP). Looking after and keeping these latrines clean are the responsibilities of the people in the neighbourhood. Unfortunately, these responsibilities are not properly followed. Consequently, these latrines are not always clean and remain filthy resulting in bad smell and vomiting. The pacca latrines are sometimes slippery and cause injuries. Sokhina, a mother of a mentally ill boy of Fulbagan Bustee shared her sad story. Two years ago, her son Faruk fell inside the latrine and badly injured his head. He was at once taken to Chittagong Medical College Hospital. He survived the head injury but became mentally ill.

However, $46 \%$ of the people in the studied neighbourhoods use kutcha (non-structured and open) latrines. These latrines either leak raw sewage into the surrounding environment or fail to prevent flies and other vermin from accessing the pit that contains the raw waste. Consequently, these latrines are considered as sources of diarrhoea, typhoid and other diseases spread by bacteria in faeces (UNICEF, 2008). Moreover, the practice of child defecation in open space, walking paths and even inside their house or the kitchen enhances health risks. However, the type of fuel used for cooking is very imperative in terms of determining the level of indoor or outdoor air pollution within a community or a neighbourhood. The socio-economic status of the people in a neighbourhood can also be understood by the type of fuel they use. High-level energy sources are cleaner but cost more and are used by households with higher levels of income. In contrast, the simpler sources of fuel, like firewood, are mainly used by households with a lower socio-economic profile. A good number of dwellers use 'Zut Kapor' (discarded garment cloths) (about 39\%), wood (about 33\%) and gas (about 22\%) as a source of fuel respectively for their everyday cooking. These 'Zut Kapor' are very cheap which costs only about 100-120 Taka for $60 \mathrm{~kg}$. Another reason for using this fuel is that it contains a relatively larger volume of fuel than any other such as wood or gas which is cost-effective. Availability of garments nearby the colony also encouraged them to use as fuel for some neighbourhoods (Fulbagan and Zahangir). On the other hand, wood is largely used in Chairman colony and Tankir Pahar along with gas supply. However, the smoke generated from burning of 'Zut Kapor' is known as 'black smoke' by the inhabitants which cause eye irritation, difficulties in breathing, headache etc. Despite knowing harmful health consequences, the poor use them for economic limitation.

The income constraints and low level of awareness also emerge the burden of waste in the poor neighbourhoods. The research revealed that approximately two-thirds of the people 
throw their domestic wastes into nearby drains. They think that this is the best way of waste disposal as the drain water carries these wastes far away from their neighbourhood. About $39.3 \%$ of the people throw their domestic wastes into open space. There is not even a single garbage bin in the neighbourhood. They usually chose a dumping site located in the middle of the neighbourhood, surrounded by houses. Few people through the wastes just beside their houses instead of the selected dumping sites. Therefore, the waste scattered everywhere in the neighbourhoods- close to living houses, kitchens, tube wells and deep tube wells, walking paths. The thrown wastes generate odour and attract flies, mosquitoes, and other insects.

\section{The pattern of Disease or Illness in the Poor Neighbourhood}

In the present study, information was collected regarding the major occurred diseases in the neighbourhood in the last two years to understand the disease pattern due to the living environment.

Table 2: Most frequently Occurred diseases in the last two years

\begin{tabular}{|l|r|r|r|r|r|r|r|r|}
\hline & $\begin{array}{r}\text { Cough } \\
(\%)\end{array}$ & $\begin{array}{r}\text { Diarrhoea } \\
(\%)\end{array}$ & $\begin{array}{r}\text { Gastric } \\
(\%)\end{array}$ & $\begin{array}{r}\text { Respiratory } \\
\text { Illness }(\%)\end{array}$ & $\begin{array}{r}\text { Scabies } \\
(\%)\end{array}$ & $\begin{array}{r}\text { Headache } \\
(\%)\end{array}$ & $\begin{array}{r}\text { Jaundice } \\
(\%)\end{array}$ & $\begin{array}{r}\text { Others } \\
(\%)\end{array}$ \\
\hline Tankir Pahar & 60 & 55 & 51 & 41 & 66 & 40 & 25 & 3 \\
\hline Zahangir Colony & 57 & 61 & 49 & 37 & 69 & 43 & 18 & 4 \\
\hline Chairman Colony & 52 & 59 & 57 & 29 & 71 & 29 & 21 & 7 \\
\hline Fulbagan Bustee & 66 & 44 & 47 & 55 & 63 & 31 & 29 & 5 \\
\hline
\end{tabular}

Source: Field survey, 2019 (Authors'own calculation)

(Note: Multiple answers have been considered)

The most frequently occurring diseases among the people are cough and cold, respiratory illness, diarrhoea, gastric/acidity, scabies, allergy, headache, and jaundice (Table 2). Of these, scabies and allergy are the most frequent diseases in the poor neighbourhoods. About $67 \%$ of the respondents reported the occurrence of this disease among at least one of their household members for at least once in the last two years. This may illustrate that poor waste disposal system, common attitude to unhygienic and high air pollution, especially plastic burning. Cough and cold is the second most frequent disease in the neighbourhoods. About $59 \%$ of the respondents reported the occurrence of this disease among at least one of their household members for at least once in the last two years. This may indicate air pollution (indoor/outdoor) in the neighbourhoods. The third most frequent disease is diarrhoea which indicates the use of unhygienic sanitation and polluted water. The percentage for the occurrence of this disease is about $55 \%$. Another disease that may have occurred on the people because of air pollution is a respiratory illness. The percentage of occurrence of this disease is about $41 \%$. There are some diseases like jaundice that may have occurred due to poor waste disposal and contaminated drinking water among the people living in the neighbourhoods. The percentage for the occurrence of this disease is about $23 \%$. During the field survey, many people were found coughing. The women were often seen continuously coughing in the kitchen as they were breathing in 'black smoke'. Some cases of diarrhoea occurrence were also seen. In fact, the gastrointestinal problems (diarrhoea and gastric/acidity) are common illness for the people of the studied neighbourhoods. Hence, oral saline and other different medicines (Nitoxin, Neoceptin-R, Pantonix, Zeldrin, Entacid Plus, Neotac, Seclo, etc.) taken 
for the cure of these gastrointestinal problems were commonly found in their houses. There are three major reasons found for the occurrence of diarrhoea and gastric/acidity among the people of the neighbourhoods:

i. Many people drink 'dirty' water from tube wells. They do not boil this water. It may be contaminated by germs and thus cause diarrhoea and gastric/acidity.

ii. There are wastes scattered everywhere in the neighbourhoods. These attract different insects and rodents that may carry the germs from the wastes and pass the germs to foods while they crawl or walk over the foods. These germs can be then passed to human bodies when they consume the foods and thus can be affected by diarrhoea and gastric/acidity.

iii. The latrines in the neighbourhoods are unhygienic. Germs can well be passed from these latrines to human bodies through the insects and rodents in the same way as mentioned before.

The children have dirt all over the clothes and the exposed part of their bodies as they play in the 'dirty' playgrounds. They were observed scratching frequently their itchy skins because of allergies or scabies. The 'dirty' playgrounds and sleeping on muddy floors of their poorly ventilated houses are reasons for the allergies and scabies.

\section{Perception of Disease/Illness}

There is a difference between disease and illness. Cassell (1978) uses illness to mean what the patients feel when they go to the doctor, and disease to mean what they have on the way home from the doctor's office. Disease, then, is something an organ has whereas illness is something a man has. According to Jennings (1986), illness is experience and that only disease can be investigated by the methods of biomedicine because the study of illness depends directly on phenomenological analysis of experienced suffering. According to him, one can be seriously diseased without being ill, [as] with silent hypertension [and] one can be seriously ill without being diseased [as] with severe depression.

In everyday life, inhabitants of poor neighbourhoods distinguish the concepts of disease and illness. They do not count some of the diseases as real, rather they think of them as illness. Cough and cold, gastric/acidity and allergy are considered as 'illnesses' by them and do not take medicines for these 'illnesses'. A shopkeeper said about these 'illnesses', "These (headache, and cough and cold) are not diseases. These are just normal illnesses. These are very usual to occur on any human." Some people perceived diseases are actually 'acts of God'. They believe that there is no way they can avoid these diseases. There is also a common belief that poor people suffer from illnesses and diseases more than rich people. Thus, 'god-given' and 'poor fate' are common notions about disease and illness among the people in the poor neighbourhood which is reflected in the voice of a respondent, "Diseases and illnesses are poor's fate; god tests patience of the poor people by giving diseases."

\section{Gender and Age Perspective of Diseases/Illness}

Studying age and gender perspective of diseases/illnesses help to understand the relative levels of risk among the people of different ages and between different genders. In the studied 
neighbourhoods, the percentages of occurrences of some of the diseases/illnesses are more frequent among females than on males (Figure-4). These diseases/illnesses are cough and cold, respiratory illness, and headache. It has been found in different studies that the black smoke' generated from cooking can cause different types of respiratory illnesses and headache (Fullerton et al., 2008). Therefore, the 'black smoke' from the burning of 'Zut Kapor' is most probably the reason why these diseases/illnesses occur on women.

The analysis of the age perspective of disease/illness suggests that there are three major diseases that occur among the children ageing less than 12 years. These diseases are scabies, allergy, and worm disease. Scabies is particularly found acute in the studied neighbourhoods. Scabies is a contagious skin infestation by the mite Sarcoptesscabiei (Gate, 2003) and may occur because of overcrowding, and sleeping habits due to limited sleeping space (Sachdev et al., 1982). The same reasons may be responsible for the occurrence of scabies among the children of the selected neighbourhoods. On the other hand, congested living place and the dirty playground are the probable reasons for the occurrence of allergy and worm disease among them.

Figure 4: Gender perspective of diseases in the study areas

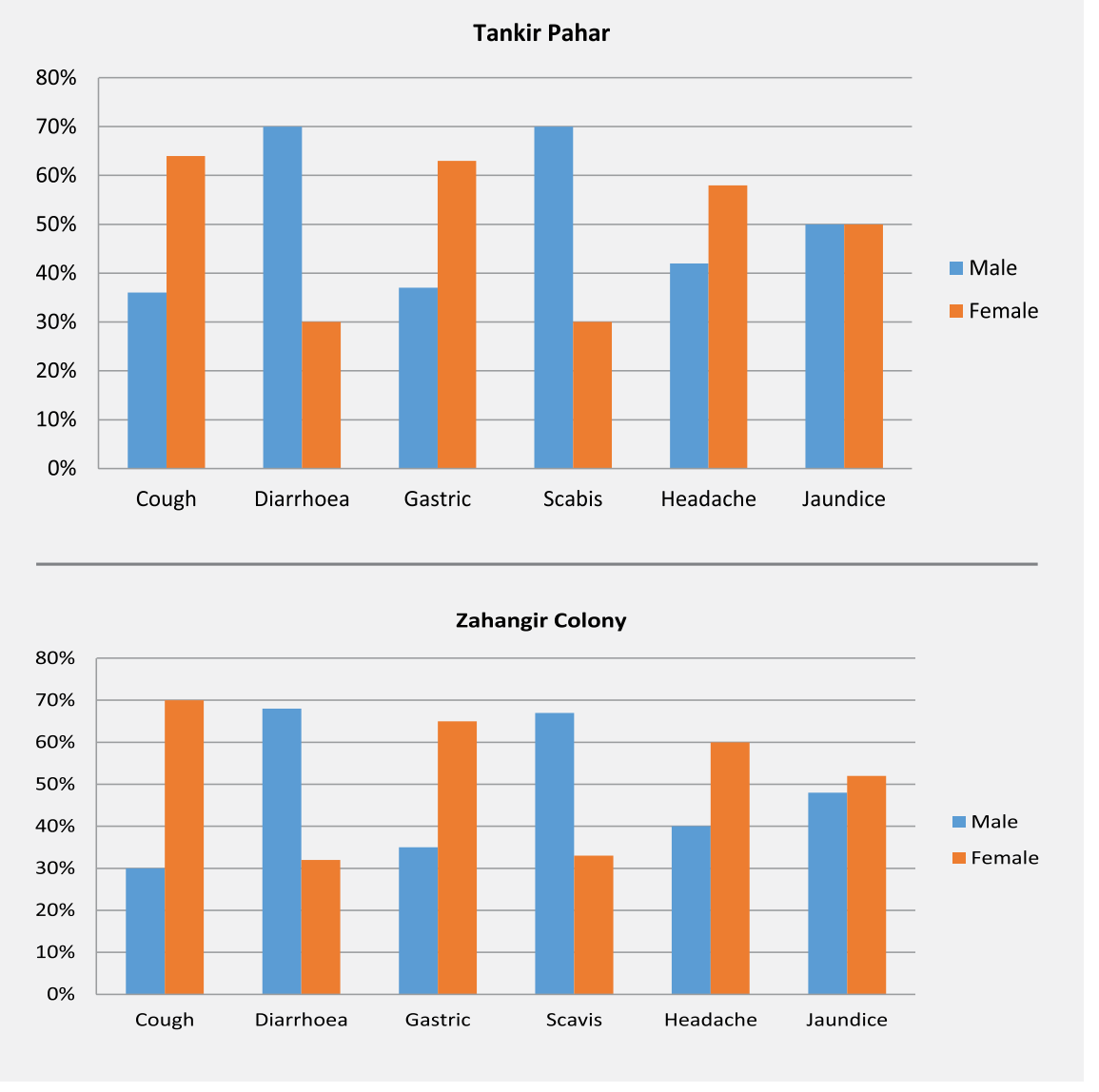



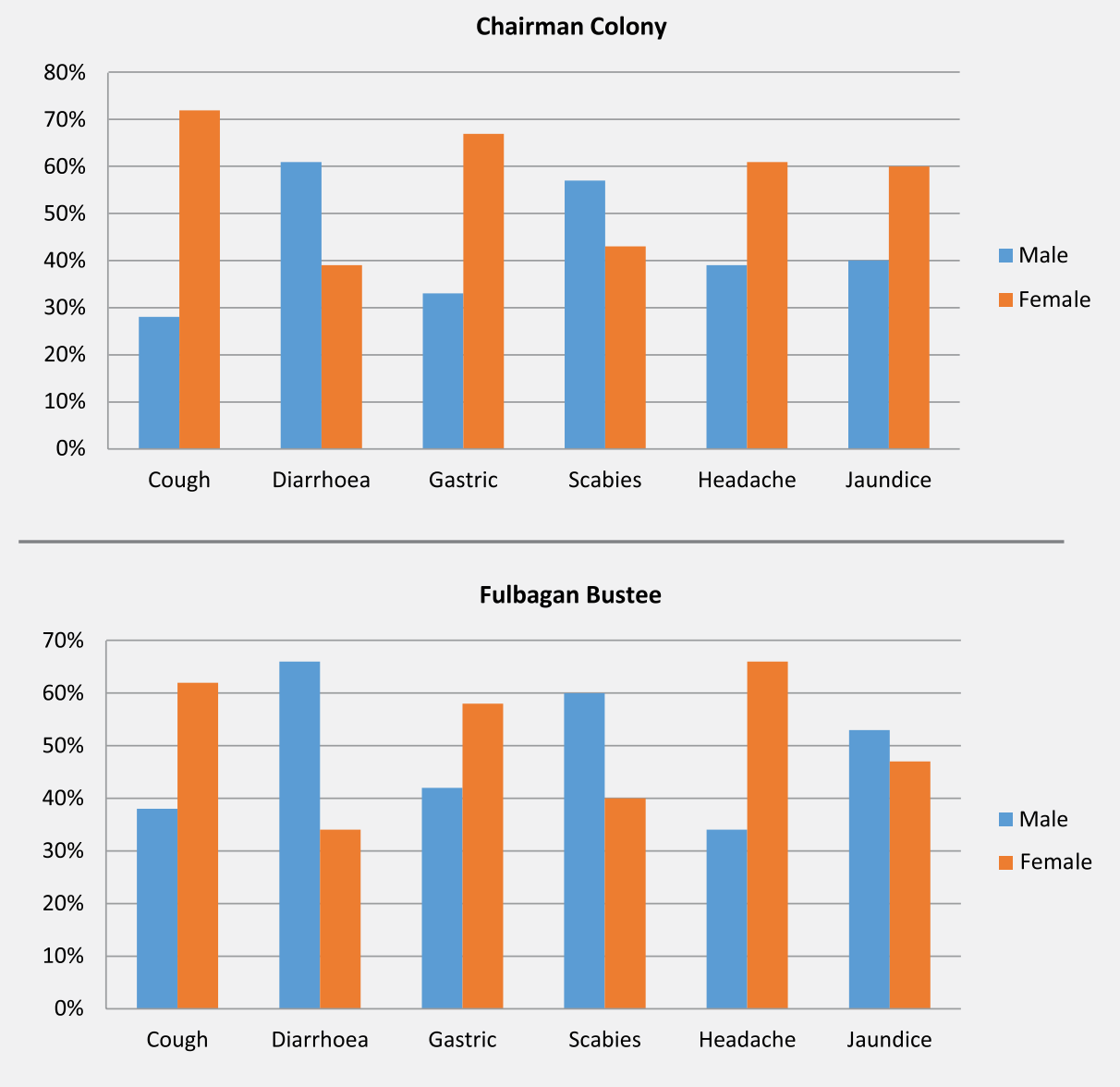

Source: Field survey, 2019 (Authors'own calculation)

\section{Conclusion}

People living in poor neighbourhoods face many physical risks due to the structural setting of the neighbourhood. The study found that the majority of the houses in the slum areas consist of only one room. The average room size of most of the houses in four study areas ranges between 101-125 square feet, although the majority of the families consist of 4-6 members. In fact, large floor space in all the houses is occupied by furniture and other household goods like water baskets, dinnerware etc. thus reducing the actual floor space available for the family members to sleep. This low actual floor space makes them think of their house as even more crowded and congested. Thus, people of the study areas think that crowding is making them more vulnerable to diseases. Generally, slum houses are characterized by poor housing materials. In the selected neighbourhoods, almost all the families share kitchens and the shared kitchens are located near unsanitary latrines that leak raw sewage into the surrounding environment. In addition, children's playgrounds are found dirty with domestic wastes.

There are different sources of risk in poor neighbourhoods. Some of these are created by the structural settings in there. Some others are created by the humans themselves, through 
their behaviours and practices. In the studied neighborhoods, people get either 'dirty' or 'iron' water, never safe and clean water. Though the majority of the people living in these poor neighbourhoods have access to sanitary latrines, these remain very dirty and unhygienic. A large portion of the people here also uses unsanitary latrines. There is no proper waste disposal system in the neighbourhoods. Thus, the environmental services provided by these neighbourhoods to their inhabitants are very poor. The environment in these neighbourhoods is largely affected by different human behaviours and practices. People here use 'Zut Kapor' that causes air pollution. They throw domestic wastes here and there that produce odour and accelerate mosquitoes and other insects menace. This condition in the neighbourhoods is raising the risk of different diseases for the people living in there. The structural setting of the neighbourhoods is also acting as a source of risk for them. But they do not possess a proper coping mechanism to reduce the physical risk. It is evident from the present research that an urban poor neighbourhood possesses very poor environmental health. The 'polluted' air and water, unhygienic sanitation facility, poor waste disposal system and inadequate housing structure in the poor neighbourhood are the major factors responsible for environmental-related health risks. These factors cause physical 'risk' of diseases and injuries to its inhabitants. The poor environmental condition, in a combination with their physical 'risks', are also generate mental sufferings among the people of the poor neighbourhood and leading them towards stigmatization. The study provides an understanding of the connection between the physical structure of the neighbourhood, and the physical and mental sufferings of its inhabitants. These sufferings can be minimized not only by the efforts of the Government and NGOs, but also with the proper efforts of local people. As the urban poor are a substantial part of the urban population, extensive and special attention should be immediately given by both the government and NGOs to improve the environmental health of the poor neighbourhoods where they live.

\section{Acknowledgement}

Authors are grateful to the Research and Publication Office, Chittagong University for the financial grant to complete the study.

\section{Conflict of Interest}

Authors have declared that no conflicting interests exist.

\section{References}

Ahmed, I. (2014). Factors in building resilience in urban slums of Dhaka, Bangladesh, procedia. Economics and Finance, 18, 745-753.

Alam, M. Z., Rahman, M. A., \& Al Firoz, M. A. (2013). Water supply and sanitation facilities in urban slums: A case study of Rajshahi city corporation slums. American Journal of Civil Engineering and Architecture, 1(1), 1-6.

Amin, A. F. M. S., Ahmad, S., \& Shamsuddin, S. A. J. (1998). Environment-friendly low-cost housing options for low-income communities. Retrieved from http://saifulamin.info/publication/conference_proceeding/c24.pdf.

Australian Government Report. (2010). Environmental health practitioner manual: A resource man- 
ual for environmental health practitioners working with aboriginal and torres strait islander communities. Retrieved from http://www.health.gov.au/internet/publications/publishing.nsf/ Content/ohp-enhealth-manual-atsi-cnt-l ohp-enhealth-manual-atsi-cnt-l-ch1 ohp-enhealthmanual-atsi-cnt-l-ch1.4.

Bangladesh Bureau of Statistics. (2015). Preliminary report on the census of slum areas and floating population 2014, Dhaka. Retrieved from http://203.112.218.65:8008/

Beggs, P.J., \& Siciliano, P.F. (2001). Spatial relationship between dwelling crowding and selected cases of morbidity in Sydney, Australia, 1994-1997. Australian Geographer, 32 (3), 377-401.

Breman, J. G., Alilio, M. S., \& Mills, A. (2004). Conquering the intolerable burden of malaria: What's new, what's needed-A summary. American Journal of Tropical Medical Hygiene, 71 (2), 1-15.

Cassell, E. J. (1978). The Healer's Art: A New Approach to the Doctor-Patient Relationship. Harmondsworth: Penguin Books.

Centre for Urban Studies. (2011). Poor Settlements in Chittagong: Mapping Urban Poor Settlements and Vacant Lands in UPPR Project Towns, Centre for Urban Studies (CUS), Dhaka. Retrieved from http://cusdhaka.org/research/mapping-urban-poor-settlements-and-vacant-lands-in27-uppr-project-towns

Chalmin, P., \& Gaillochet, C. (2009). From waste to resource, an abstract of world waste survey. Cyclope, Veolia Environmental Services, Edition Economica, France.

Cohen, A. J., Anderson, H. R., Ostro, B., Pandey, K. D., Krzyzanowski, M., Künzli, N., ... \& Smith, K. R. (2004). Urban air pollution. Comparative quantification of health risks: global and regional burden of disease attributable to selected major risk factors, 2, 1353-1433.

Conway, J. (1993). Ill-health and Homelessness: the Effects of Living in Bed-and-breakfast accommodation, In: Burridge, R. and Ormandy, D. (eds.) Unhealthy Housing: Research, Remedies and Refor. NY: Spon Press, New York, 283-300.

Dunn, J. (2002). Housing and inequalities in health: A study of socioeconomic dimensions and housing and self-reported health from a survey of Vancouver residents. Journal of Epidemiology and Community Health, 56, 671-681.

Ellen, I. G. and Turner, M. A. (1997). Does Neighbourhood Matter? Assessing Recent Evidence. Housing Policy Debate, 8(4), 833-866.

Fonseca, W., Kirkwood, B. R., Victora, C. G., Fuchs, S. R., Flores, J. A., \& Misago, C. (1996). Risk factors for childhood pneumonia among the urban poor in Fortaleza, Brazil: A case--control study. Bulletin of the World Health Organization, 74(2), 199-208.

Fullerton, D. G., Bruce, N., \& Stephen, B. (2008). Indoor air pollution from biomass fuel smoke is a major health concern in the developing world. Transactions of The Royal Society of Tropical Medicine and Hygiene, 102 (9), 843-851.

Gates, R. H. (2003). Infectious disease secrets. Elsevier Health Sciences. Book

Gurumukhi, K. T. (1984). Locational aspects of housing for low-income groups in metropolitan situations, International Conference on Low-cost Housing for Developing Countries. Paper Presented at: CBRI,Roorkee, India.

Haider, M. R., Rahman, M. M., Islam, F., \& Khan, M. M. (2016) Association of low birth weight and indoor air pollution: biomass fuel use in Bangladesh. Journal of Health and Pollution. (6) 11, 18-25.

Hastings, A., Flint, J., McKenzie, C., \& Mills, C. (2005). Environmental problems and service provision in deprived and more affluent neighbourhoods. Retrieved from https://www.jrf.org.uk/report/ environmental-problems-and-service-provision-deprived-and-more-affluent-neighbourhoods

Heukelbach, J., De Oliveira, F. A. S., Kerr-Pontes, L. R. S., \& Feldmeier, H. (2001). Risk factors as- 
sociated with an outbreak of dengue fever in a favela in Fortaleza, north-east Brazil. Tropical Medicine \& International Health, 6(8), 635-642.

Hossain, M. A., Moniruzzaman, M., \& Islam, M. A. (2010). Urban environmental health in Bangladesh slum: A comparative study of two metropolitan cities. Journal of science foundation, 8(1-2), 67-76.

Hutton, G., Haller, L., \& Water, S. (2004). Evaluation of the costs and benefits of water and sanitation improvements at the global level. World Health Organization. Geneva. Retrieved from https:// www.who.int/water sanitation health/wsho404.pdf

Islam, N. et al. (2006). Slums of urban Bangladesh: Mapping and census 2005. Centre for urban studies, Dhaka. Retrieved from https://www.measureevaluation.org/resources/publications/tr-06-35

Ivanov, I. D., Licari, L., \& Bertollini, R. (2004). Health and the Environment in the WHO European Region: Situation and Policy at the Beginning of the 21st Century. Paper presented at Fourth Ministerial Conference on Environment and Health, Budapest, WHO Regional Office for Europe.

Jennings, D. (1986). The Confusion between Disease and Illness in Clinical Medicine. Canadian Medical Association Journal, 135, 865-870.

Kempson, E. (1999). Overcrowding in Bangladeshi households: a case study of Tower Hamlets, London, Policy Studies Institute.

Kitchin, R., \& Tate, N. J. (2000) Conducting research in human geography: theory, methodology and practice. Pearson, London.

Krieger, J., \& Higgins, D. L. (2002). Housing and health: Time again for public health action. Retrieved from http://www.ncbi.nlm.nih.gov/pmc/articles/PMC1447157.

Lucich, M. (2011). The value of play. Retrieved from http://www.education.com/reference/article/ Ref_Value_Play/.

Maksudur Rahman, M., Haughton, G., \& Jonas, A. E. (2010). The challenges of local environmental problems facing the urban poor in Chittagong, Bangladesh: a scale-sensitive analysis. Environment and Urbanization, 22(2), 561-578.

Mannan, M. A. (2017). Burden of disease on the urban poor: A study of morbidity and utilization of healthcare among slum dwellers in Dhaka city. Bangladesh Institute of Development Studies. Retrieved from http://hdl.handle.net/11540/7953.

Morgan, M. T. (1991). Environmental health. WCB Brown and Benchmark Publishers, Oxford.

NPR. (2014). When a home poses health risks, the floor may be the culprit. Retrieved from http:// www.npr.org/sections/goatsandsoda/2014/o9/02/342447826/when-a-home-poses-healthrisks-the-floor-may-be-the-culprit.

Perry, B., Hogan, L., \& Marlin, S. (2000). Curiosity, pleasure and play: A neurodevelopment perspective. Retrieved from https://childtrauma.org/wpcontent/uploads/2014/12/CuriosityPleasurePlay_Perry.pdf.

Prosun, P. (2011). The Lift house: An amphibious strategy for sustainable and affordable housing for the urban poor in flood-prone Bangladesh. Retrieved from http://www.buoyantfoundation.org/ pdfs/prosun_prithula.pdf.

Prüss-Üstün, A. \& Corvalán, C. (2006). Preventing disease through healthy environments: Towards an estimate of the environmental burden of disease. World Health Organization. Geneva. Retrieved from https://www.who.int/quantifying ehimpacts/publications/preventing-disease/en/

Rahman A. and Rahman M. M. (2012) Water Crisis in the Urban Poor Areas of Chittagong City, Oriental Geographer, 54 (1 \& 2), 43-57.

Rivkin, M. (2000). Outdoor experiences for young children. Retrieved from http://www.ericdigests. org/2001-3/children.htm. 
Sachdev, T. R., Gulati, P. V., \& Prasad, P. (1982). A study on prevalence of scabies in a resettlement colony (slum area) and its association with some sociocultural and environmental factors. Journal of Indian Association for Communicable Diseases, 5(3-4), 88-91.

Sanbata, H., Asfaw, A., \& Kumie, A. (2014). Indoor air pollution in slum neighbourhoods of Addis Ababa, Ethiopia. Atmospheric Environment, 89, 230-234.

Sears, M. E., \& Genuis, S. J. (2012). Environmental determinants of chronic disease and medical approaches: recognition, avoidance, supportive therapy, and detoxification. Journal of environmental and public health, 2012.

Shil, S. R. (2013). A study on lifestyle and disease pattern of slum dwellers in Dhaka city. Department of Pharmacy, East West University, Dhaka.

Smith, K. R., \& Ezzati, M. (2005). How environmental health risks change with development: the epidemiologic and environmental risk transitions revisited. Annual Review of Environment and Resources. 30, 291-333.

Smith, K. R., Corvalán, C. F., \& Kjellström, T. (1999). How much global ill health is attributable to environmental factors?. Epidemiology, 573-584.

Smith, K. R., Samet, J. M., Romieu, I., \& Bruce, N. (2000). Indoor air pollution in developing countries and acute lower respiratory infections in children. Thorax, 55(6), 518-532.

Stein, L. (1950). A study of respiratory tuberculosis in relation to housing conditions in Edinburgh. I. The pre-war period. British journal of social medicine, 4(3), 143-169. doi:10.1136/jech.4.3.143.

UN Habitat. (1996). The human settlements condition of the world's urban poor. United Nations Centre for Human Settlements (Habitat), Nairobi. Retrieved from http://collections.infocollections. org/ukedu/en/

UNEP. (2010). Framework of global partnership on waste management, note by secretariat. Retreieved from http://www.unep.or.jp/Ietc/SPC/news nov10/3_FrameworkOfGPWM.pdf

UNICEF. (2008). Rural sanitation, hygiene and water supply. Retrieved from http://www.unicef.org/ bangladesh/RURAL_Water_Sanitation_and_Hygiene.pdf.

UNICEF. (2011). Urban water challenges in Bangladesh. Retrieved from http://www.unicef.org/bangladesh/Urban_water_challenges_in_Bangladesh.pdf.

VanEenwyk, J. \& Brandt, G. (2013). Social and economic determinants of health. Retrieved from https://www.afro.who.int/health-topics/social-and-economic-determinants-health

WHO. (2008). Environmental health. World Health Organization (WHO). Geneva. Retrieved from https://www.who.int/mediacentre/infographic/environment/en/

WHO. (2015). What are the health risks related to overcrowding?. Retrieved from http://www.who.int/ water_sanitation_health/emergencies/qa/emergencies_qa9/en/.

World Bank Report. (2018). Health and nutrition in urban Bangladesh: social determinants and health sector governance, World Bank Group, Dhaka. Retrieved from http://documents.worldbank. org/curated/en/399461514540007634/pdf/122330-Pub-Public-Pubdate-12-28-17.pdf

Xu, X., Niu, T., \& Christian, D. (1996). Occupational and environmental risk factors for asthma in rural communities in China. International Journal of Occupational and Environmental Health. 2(3), $172-176$. 